\title{
Stroke: Prevention is better than cure. Early education is the way forward
}

\author{
Mohamed Saufi Awang* \\ Consultant Neurosurgeon, Department of Surgery, School of Medicine, International Islamic University, Malaysia
}

Stroke is a global health problem which is associated with morbidity and mortality. In Malaysia, stroke is one of the top five leading causes of death $[1,2]$. According to the Third National Health and Morbidity Survey (NHMS) in 2006, the prevalence of stroke was estimated to be $0.3 \%$ and progressively increased in trend. The fourth NHMS in 2011 reported the incidence as $0.7 \%$. The mean age of stroke patients is between 54.5 to 62.6 years with male preponderance $[1,2]$.

Approximately $80 \%$ of stroke cases in Malaysia are ischemic in origin and the remaining as hemorrhagic. This is comparable with reported data from other countries $[3,4]$. There are many stroke-related risk factors. These can be divided into modifiable and non-modifiable factors such as age, sex and race. Hypertension is the major modifiable risk factor for stroke accounting for $53.2-62.6 \%$ followed by diabetes mellitus (27.4-55.2\%) and hypercholesterolemia (4.8-37.3\%). Other risk factors include smoking, ischemic heart disease and history of transient ischemic attack [1-8].

Stroke can cause high level of emotional and physical distress to both the patient and caregiver and carries a substantial burden to the government. For major stroke, the average hospital-stay is estimated around 9.8 days and 3.6 days for minor stroke. The estimated cost of admission for major stroke is MYR 9000 and MYR 3353 for minor stroke $[1,9]$.

Prevention is always better than cure. Early education should be the best method for government to move forward. School children should be taught about healthy diet and lifestyle. These subjects should be included in the curriculum and continuously taught from primary school up to higher level.

Malaysia is the most obese country in Asia. The 2015 NHMS reported that 5.6 million of adult age 18 and above was overweight and 3.3 million was obese. The abundance of food and to some extent changing to Western diet is responsible for high obesity rate in Malaysia.

Poor lifestyle posed a serious threat to life and health. Smoking habit among school children and adolescents are alarming [10]. Twenty years ago, it is almost difficult to see young female adolescent to smoke in the street or café. Nowadays, it has become a trend and lifestyle. Lack of exercise is another major contributing factor to obesity. Sedentary lifestyle doubles the risk of coronary heart disease, diabetes and obesity $[1,10]$.

As a conclusion, government should concentrate on this younger generation. The knowledge and exposure of healthy diet and lifestyle must begin early in life. More importantly, this process must be constant at all level of education.

\section{References}

1. Cheah WK, Hor CP, Zariah AA, Looi I (2016) A review of stroke research in Malaysia from 2000 - 2014. Med J Malaysia 71: 58-69. [Crossref]

2. Low KW, Gan SH (2012) Burden of stroke in Malaysia. Int J Stroke 7: 165-167. [Crossref]

3. Jaya F, Win MN, Abdullah MR, Abdullah MR, Abdullah JM (2002) Stroke patterns in Northeast Malaysia: A hospital-based prospective study. Neuroepidemiology 21: 2835. [Crossref]

4. Neelamegam M, Looi I, Cheah WK, Narayanan P, Hamid AM, Ong LM (2013) Stroke incidence in the South West District of the Penang Island, Malaysia: PEARLs: Penang acute stroke research longitudinal study. Prev Med 57: S77-S79. [Crossref]

5. Amal NM, Paramesarvathy R, Tee GH, Gurpreet K, Karuthan C (2011) Prevalence of chronic illness and health seeking behaviour in Malaysian population: Results from the third national health morbidity survey (NHMS III) 2006. Med J Malaysia 66: 36-41. [Crossref]

6. MOH Malaysia. National Health and Morbidity Survey 2011 Report: Institute of Public Health.

7. Ong TZ, Raymond AA (2002) Risk factors for stroke and predictors of one-month mortality. Singapore Med J 43: 517-521. [Crossref]

8. Hamidon B, Raymond AA (2003) Predictors of in-hospital mortality after an acute ischaemic stroke. Neurol J Southeast Asia 8: 5-8.

9. Aznida FAA, Azlin NMN, Amrizal MN, Saperi S, M AS (2012) The cost of treating an acute ischaemic stroke event and follow-up at a teaching hospital in Malaysia: A casemix costing analysis. BMC Health Serv Res 12: P6.

10. MOH Malaysia. National health and morbidity survey 2015 Report. Non- communicable diseases, risk factors and other health problems: Institute of public health.
Copyright: (C2017 Awang MS.This is an open-access article distributed under the terms of the Creative Commons Attribution License, which permits unrestricted use, distribution, and reproduction in any medium, provided the original author and source are credited.
Correspondence to: Mohamed Saufi Awang, Consultant Neurosurgeon, Department of Surgery, School of Medicine, International Islamic University, Malaysia, E-mail: saufiawang@iium.edu.my

Received: October 19, 2017; Accepted: October 30, 2017; Published: November 02,2017 